\title{
MEDIEVALIZEM: OD RUSKINA K CHESTERTONU
}

Ključne besede: srednji vek, recepcija, medievalizem, medievistika, medievaleskno, umetnostna zgodovina, objektivnosubjektivno

Namen pričujočega članka je na kratko orisati problematiko medievalizma in medievistike, in sicer $\mathrm{v}$ časovnem razponu od njunih začetkov, ali natančneje vzpostavitve, $v$ devetnajstem stoletju do vključno prve polovice dvajsetega stoletja. V ospredju bodo predvsem tiste bistvene premene oziroma vsaj minimalni zasuki znotraj izbranega polja, ki naj jih tu zaenkrat povzame premik od Johna Ruskina h Gilbertu Keithu Chestertonu, ki na sebi lasten in vsekakor širše pomenljiv način povzame in zasuka Ruskinovo dediščino, s tem pa dediščino, grobo rečeno, celotnega devetnajstega stoletja (Simmons, 2001, 131-143). ${ }^{1}$

1 Chene Heady, Heraldry and Red Hats: Linguistic Skepticism and Chesterton's Revision of Ruskinian Medievalism. Kot je razvidno že iz naslova (»linguistic skepticism«), gre predvsem za vprašanje jezika oziroma znakovnih sistemov, kot temu pravi Chesterton. Glede na dostopnost del velja opozoriti na paralelno branje Chestertona (1961) in Ruskina (1979). Premik iz devetnajstega v prvo polovico dvajsetega stoletja, ki ga tu na lasten način osvetljujem, bi sam poimenoval Ruskin/Chesterton. Pričujoči članek ni še ena izmed številnih analiz njunih del. Interpretacija Chena Headyja služi kot osnova za bolj razširjen razmislek o problematiki, ki jo je nakazal avtor omenjenega članka. 


\section{Medievalizem, medievistika, medievalistika, medievaleskno}

Kaj pravzaprav je medievizem oziroma medievalizem in kaj označuje, seveda tudi v opoziciji do akademske medievistike? ${ }^{2}$ Najbolj splošna in morda zato dokaj ohlapna definicija medievalizma je vsakršna recepcija srednjega veka na katerikoli ravni, naj bo ta akademska, uradna, torej znanstvena, ali pa pogojno rečeno nižja, opredeljena kot neznanstvena, ljudska, torej popularna, vključujoč vmesni spekter bolj ali manj nedoločljivega in nerazločljivega. ${ }^{3}$ Definicija ima še drugo, bolj problematično plat, še posebej če upoštevamo tuje terminološke zagate: ${ }^{4} »$ medievalizem «, če ga sedaj dojamemo kot vejo medievistike, torej kot medievalistiko, je tudi študij ali proučevanje pisanja zgodovine srednjega veka, torej samega procesa pisanja in proučevanja recepcije. Premik, ki je tu dobesedno na delu, je premik od »kaj« h »kako«. Tako bi lahko že na samem začetku zaključili naslednje: medievistika kot uradna veja proučevanja in postavljanja pravega, nepotvorjenega srednjega veka ima vejo, ki se ukvarja izključno s samim proučevanjem, postavljanjem srednjega veka, pisanjem zgodovine, nenazadnje problemi jezika in vsemi možnimi recepcijami, ki gredo onstran, prek minimalnega odmika, kot v obratu k sebi, k mišljenju same medievistike, torej medievistike kot take in s tem srednjega veka kot objekta raziskovanja.

2 Termin medievalizem je dobesedni prevod angleške besede, ki spada v krog t. i. medieval studies, tj. srednjeveških študij, ki zajemajo vprašanje o medievalizmu oziroma recepciji. Tu se ne odločam za rabo slovenjenega prevoda, torej za medievizem. Razlog je predvsem v pridevniški rabi besede, in sicer zavoljo večje, čeprav včasih težko dosegljive razločnosti med akademsko in neakademsko, uradno in pogojno rečeno neuradno sfero: recimo med medievalističnim in medievističnim tekstom ali splošneje delom. Na neki način je celotni problem, kar problematika, jasno viden že v rabi besed. Ostali - in nastali - terminološki problemi in odločitve bodo pojasnjeni v nadaljevanju članka.

3 Vprašanje recepcije se je razvilo znotraj komparativistike in literarne zgodovine. Najprejin predvsem - gre za vprašanje občinstva in bralcev oziroma gledalcev. Od tod se je razširilo na druga polja, še posebej po letu 1960. Gl. Simons, 1992. Medievalizem se je, lahko bi rekli, uradno, pričel leta 1972, z znanstveno revijo Studies in Medievalism, glavni pobudnik pa je bil Leslie J. Workman.

$4 \mathrm{~V}$ angleškem prostoru lahko medievalism označuje recepcijo (pisano $\mathrm{z}$ malo začetnico) ali študij recepcije (pisano $\mathrm{z}$ veliko začetnico), poleg medieval studies. $\mathrm{V}$ nemškem prostoru naletimo na ločevanje Mittelalterrezeption ali Mädievalismus in Mädievistik, enako v francoskem: la réception du Moyen Âge ali le médiévalisme, ki je včasih skoraj izključno la modernité du Moyen Âge, in les études du Moyen Âge. 
Nedvomno bi se tu dalo oporekati, češ da je takšno razločevanje med medievistiko in medievalistiko nepotrebno, da imamo opraviti zgolj z enim ali drugim imenom, da velja razlikovanje ohraniti zgolj zato, da laže opredelimo tekste, ki se nanašajo izključno na pisanje o srednjem veku ali pisanje srednjega veka in pisanje o pisanju srednjega veka. Vendar pa je vsak strogo historiografski medievistični tekst na videz usmerjen izključno v objekt, ki je srednji vek ali srednjeveško delo, in je tako vselej že tekst, ki je hote ali nehote medievalističen, ki piše o pisanju samega pisanja - vseskozi je po pravilu minimalno samonanašalen in $\mathrm{v}$ sebi podvojen.

Medievalizem je torej nekakšna točka napetosti, mesto dvoreznega in/ali samonanašalnega, kamor vdira vse tuje, je sámo vdiranje tujega, obenem pa je tudi mesto, kjer medievalizem - tudi kot povsem napačna recepcija ali kar oponašalnost, pasticcio medievalesknega kot najbolj vulgaren primer recepcije, predvsem kot vživljanja, kakor da bi bila določena komponenta uradne veje vzeta dobesedno - ni več izkušen kot zunanje polje medievistike, pri čemer sovpade oziroma se izkaže kot notranja zunanjost ali zunanja notranjost samega polja medievistike. Bolje rečeno: polje se tu preuredi, meje se zabrišejo, zunanja meja postane notranja limita, domena raziskovanja se razširi najprej v študije o srednjem veku, sedaj vključujoč nezunanjo ali neakademsko sfero, najsplošneje rečeno pa gre za razširitev, skozi prevoj vase, v kakršno koli recepcijo srednjega veka. ${ }^{5}$ To seveda prinaša določene posledice, predvsem $\mathrm{z}$ gledišča avtentičnega, preverjenega ali para laž/resnica, obenem pa tudi z gledišča pozicije znanstvenika: medievist in medievalist, slednje $\mathrm{v}$ obeh pomenih besede, torej tudi kot sled ljubiteljstva, ne zgolj kolikor toliko razsvetljenega poznavalstva in seveda ne v znamenitem smislu, ki mu ga je podelil Erwin Panofsky. ${ }^{6}$ Medievalistika kot medievistika, ki se misli oziroma poskuša misliti, bi tu, sledeč logiki metagovorice, razločevanje pravega od nepravega, potvorjenega srednjega veka prenesla na drugo raven, na svoje lastno polje, skušala bi seči za lasten

5 Premik je lepo nakazan že v samem naslovu zbornika, ki ga je uredil John Simons (1992): od srednjeveškega $\mathrm{k}$ medievalističnemu.

6 Pierre Bourdieu umetnostni zgodovini očita prav to: da se v resnici, torej do njegovega časa, zgodnjih sedemdesetih let, ni znebila ljubiteljstva in spiritualizma, ki spremlja gorečnost faktičnosti. Faktičnost in zanesenjaštvo (Holsinger, 2003, 94-113). To dvojnost najdemo pri Georgeu Stubbsu (gl. Biddick, 1998). 
hrbet in se zajeti, pravzaprav vsakič znova notranje očistiti. Temeljni poudarek je tako vselej tudi na procesu notranjega očiščevanja.

John Ruskin je leta 1853 v enem od znamenitih edinburških predavanj, $s$ katerim je želel podpreti predrafaelitsko umetnost, uporabil besedo mediaevalism, pravzaprav ji je dodelil status termina (Simmons, 2001, 1). ${ }^{7}$ $\mathrm{Z}$ besedo, katere končnico je nedvomno zelo pomembno opaziti, je skušal opisati, če ne zaobjeti, navdušenje lastne generacije nad srednjim vekom, kot je bil tedaj, časovno in drugače, opredeljen, in nad srednjeveškimi deli oziroma spomeniki. Beseda označuje tudi spremembo v gledanju srednjeveškega, ki sedaj ni konotirano $\mathrm{z}$ mračnjaškim, temveč gre $\mathrm{v}$ njegovo nasprotje. Kot pripominja Clare A. Simmons, je termin medievalizem nastal in se uveljavil prav v devetnajstem stoletju, nekoliko pred Ruskinom, poprej se je bolj ali manj, vsaj v angleško govorečem prostoru, kjer se je medievalizem rodil, uporabljala zgolj označitev srednjeveško ali srednji vek. Ključna razlika med Ruskinovo in današnjo rabo termina je predvsem v pojmovanju navdušenja, raziskovanja, inkorporiranja ali struje, tj. -izma: pri Ruskinu medievalizem obenem označuje neko dobo, in sicer dobo med klasikalizmom, ne klasicizmom, in modernizmom, dojetim kot moderna doba, kot Ruskinov čas, tedanjost (Simmons, 2001, 2). Pravzaprav označuje dve dobi, vpisan je dvakrat: meri na sam srednji vek in obenem na dobo navdušenja nad srednjim vekom. V slednjem je že navzoče neko oprijemanje idealov, vprašanje izvora, ki na videz strogo nasprotuje moderni dobi padca ali izgube nedolžnosti, in če se spomnimo na še enega velikega medievalista, s tega zornega kota precej dvoumno figuro Williama Morrisa (Biddick, 1998, 36-57), ${ }^{8}$ tudi industrijskemu kapitalizmu devetnajstega

7 Predrafaelite je javno podpiral tudi z rednimi članki v časopisu The Times. Gl. Ruskin, 1907: delo ni še ponatisnjeno, dostopno je v elektronski obliki: http://www.archive.org/stream/ lecturesonarchit033432mbp.

Morris se po eni strani zavzema za avtentično, je proti potvorbam, sanja o vsem, kar njegovemu času nasprotuje, torej industrializaciji, ki uničuje ideale, po drugi strani pa v njej sodeluje s proizvodnjo gotizirajoče ornamentike, ki »nehote« briše razliko med izvirnikom in kopijo. Zanimiv, pravzaprav več kot pričujoč in v celoti v skladu s srednjeveškim idealom je obrat k mojstrstvu, veščini, spretnosti, ornamentiki, k dekoraciji, nazadnje k rokodelstvu in obrti: prav tu je srž problema, prav tu je treba iskati odpor proti moderni dobi, ki pa je vanjo že vpisan in v njej sodeluje, saj ga kot ideal poraja sama doba $\mathrm{z}$ vsemi svojimi zagatami. Ne gre preprosto za padec $\mathrm{v}$ predmoderno. $Z$ gledišča moderne umetnosti je problem jasno opredeljiv: komponenta moderne, recimo v smeri modernega slikarstva, je prav razvelja- 
stoletja, umetniškemu trgu in pojmovanju statusa umetnika, ločenega ali odtujenega od svojega dela, v obeh pomenih besede. Seveda lahko medievalizem v svoji mnogoterosti in raznolikosti služi tudi kot obramba določenega družbenega stanja ali sistema, prav moderne dobe, zopet hote ali nehote.

Trojica dob torej ne pomeni treh umetnostnih slogov, temveč gre vselej za nanos na lasten čas, za tri različne, glede na sinhrono religiozno opredeljene življenjske sloge: za predkrščanski, krščanski in z moderno dobo postkrščanski slog ali - kar je nadvse pomenljivo - »način življenja«, »življenjski slog«. Krščanskega ali medievalističnega, v tem primeru kar (imaginarno) srednjeveškega, predstavlja vzor srednjeveškega mojstra, fikcija "gotskega deželana«, do popolnosti spojenega s svojo veščino, brez najmanjše distance ali razmika, ki ga med mesto, skozi "poklic« in osebo, ki to mesto sedaj le za določen čas zavzema, vpelje moderna. Ni odveč opaziti, da je ta distanca ali razmik že nastavek za vzpostavitev treh dob, da je vanje pravzaprav vpisan in da je podlaga, na kateri poganja ideal srednjeveškega mojstra. Morebiti bi zato lahko sklepali na sledeče: samo opredeljevanje sloni na premiku, na mišljenju vmesnosti ali zasuka iz krščanskega $v$ postkrščanski življenjski slog, v katerem živi Ruskin. Natanko to je zastavek, celo stava opredeljevanja dob: misliti lasten čas, sedanjost, se ji celo izmakniti, ponuditi zdravilo za njene zagate. Vsekakor velja poudariti iskanje preboja glede na lasten čas, ki pa velikokrat izkazuje stremljenje po iz časa izvzeti poziciji. To je treba zadržati še posebej pri vprašanju jezika in interpretacije. Ključnega in zagotovo nesamoumevnega pomena je naslednje: medievalizem omogoča oziroma vzpostavlja ločitev, ki se vzpostavi naknadno, skozi izgubo, zavedanje ali občutje izgube, zaradi česar ga bodo vselej spremljale besede, kot so žalovanje, melanholija, minevanje in umiranje. Zaradi naknadnosti njegove korenine, seveda aposteriorno, a upravičeno, iščemo najprej v trenutkih, ko vznikne termin »srednje«, kar se najprej zgodi z nastopom italijanske renesanse. Že Herbert Kessler preprosto opomni,

vitev obrtniške ali tehnične plati, obenem je razveljavitev mojstrstva, tudi kot sprezzature: "No, torej, ni kaj videti, poleg tega pa ni niti dobro naslikano. Malevičeva slika leta $1915 \mathrm{v}$ strogem pomenu [za nazaj] izpostavi šušmarstvo slikarstva.« (Wajcman, 2007, 43) 
da v srednjeveških dokumentih in spomenikih ne zasledimo nikakršnega zavedanja o media aetas (Kessler, 1988, 166). ${ }^{9}$

Potemtakem ni presenetljivo, da je pri vprašanju recepcije srednjega veka treba vseskozi upoštevati družbeno-kulturne okoliščine, in sicer poleg dejstva, da recepcija, enako kot percepcija, ni pasivna, da imamo pri sprejemanju, fascinaciji in navdušenju vsakič opraviti z minimalnim deležem aktivnega, spreminjajočega in posegajočega $\mathrm{v}$ tisto, $\operatorname{kar} z$ navdušenjem na videz preprosto sprejmemo. $Z$ drugimi besedami: po eni strani je polje recepcije skozi iluzijo vnazajšnjosti vselej že tu in tisto, kar je sprejeto pri čemer sta tudi odklonilnost ali nenaklonjenost že recepcija -, naleti na plodna, kakor da že pripravljena tla. Medievalizem kot recepcija tako ni zrcaljenje, odsev ali odražanje tega ali onega časa, temveč je že čas na medievalizmu lastni ravni, z vsemi svojimi zagatami in slepimi ulicami, vselej $\mathrm{z}$ vidika krščanstva oziroma slabljenja dimenzije božjega ali svetega. ${ }^{10}$ Po drugi strani pa je recepcija tudi že ustanavljanje, vzpostavljanje tistega, kar je na videz zgolj sprejeto. Ustvarjeno je, a ima videz najdenega, odkritega ali razkritega:

"Srednji vek je med drugimi obdobji ali polji zgodovinskih študij tako rekoč edinstven, saj je v celoti stvaritev znanstvenikov. Termin »srednji vek«, ki je ena izmed številnih oblik, so prvi postavili renesančni humanisti, odtlej pa so si vsi nadaljnji kulturni preobrati, vse do romantike in vključno z njo, termin skušali prisvojiti in ga razširiti za lastne potrebe. Vsaka generacija mora po pravilu napisati lastno zgodovino preteklosti, kar še posebej drži za primer srednjega veka. Medievalizem, proučevanje tega procesa, je zato nujni sestavni del študij o srednjem veku. [...] Medievalizem zanima bolj proces kot produkt [...]«(Workman, 1995, 227)

9 Zahvaljujem se Nataši Golob, ki me je na omenjeni članek opozorila.

10 Seveda tu ne gre za historicizem utapljanja del v kontekstu, kar bo razvidno iz nadaljevanja pričujočega članka. Umetniško delo, splošneje rečeno umetnost, gre vsakič minimalno proti toku, torej minimalno "uhaja « družbeno-kulturnemu kontekstu, kar je drugače mogoče najlepše pokazati - in umetnost to kaže - prav na primerih, ki so na določen kontekst, še posebej politično-ideološki, karseda tesno vezani. Umetnost tako nikdar ni zrcaljenje, ni odražanje - nima zunanje pozicije. Gl. uvodne primere v Žižek (1997). Tu je ključnega pomena mišljenje materialne zunanjosti oziroma iskrenosti. 
»Medievalizem je študij srednjega veka, nanos srednjeveških modelov na sodobne potrebe in navdih srednjega veka v vseh oblikah umetnosti in misli.« (Workman, 1987, 1)

Primerov takšnega nanosa ali aplikacije ni malo, pri čemer sam nanos ali aplikacija spremeni tudi tisto, kar je naneseno, raba namreč spreminja tisto, kar sama nanaša in na kar se nanaša. Najboljšo opredelitev štirih modelov medievalizma oziroma modelov recepcije, tudi aplikacij srednjega veka, ki ga vsaka na svoj način vzpostavljajo, vselej v medsebojni prepletenosti, sta podala Francis Gentry in Ulrich Müller (Gentry, 1991, 401). Njuna razdelitev je temu primerno široko zastavljena in lahko služi pri obravnavi recepcije (vsaj) drugih slogov ali zgodovinskih dob. Prvi model ali modus recepcije je kreativni. Kreativna recepcija pomeni, da so srednjeveške vsebine, teme, avtorji in dela tudi že medievistična in medievalistična dela, kreativno vključena ali inkorporirana v neko novo delo. Sem lahko uvrstimo marsikaj: od citiranja, komentiranja in muzejskih postavitev do nanašanja na to ali ono delo, recimo znotraj likovne umetnosti v prvi polovici dvajsetega stoletja: nanašanje na starorusko ikono v ruski avantgardi, srednjeveško kiparstvo pri Ernstu Barlachu, gotsko okensko slikarstvo pri Georgesu Rouaultu itn. Druga vrsta recepcije je reproduktivna: izvirna oblika srednjeveškega dela je rekonstruirana na način, ki je v določenem časovnem obdobju ali lokaliteti dojet kot avtentičen oziroma pravilen, na primer izvajanje glasbenih del, tudi renovacije oziroma restavriranje, rekonstruiranje del, ustvarjanje čim bolj natančnega približka, ki postane stvar sama. Sledi ji akademska recepcija, ki pomeni proučevanje, konstrukcijo in interpretiranje ter sledi določenim kriterijem in kritičnim metodam te ali one znanstvene discipline. Zadnji in morda najpomembnejši modus recepcije je politično-ideološka recepcija srednjega veka: v Franciji devetnajstega stoletja bomo našli dva srednja veka, rojalističnega in republikanskega, ${ }^{11}$ semkaj lahko vnesemo tudi socialni oziroma socialistični srednji vek Williama Morrisa. Posebno vprašanje je seveda vprašanje nacizma in srednjega veka, recepcije v času obeh vojn, zelo zanimiva sta tudi kolonializem in eksotizem, saj je logika, ki ju vodi, skupaj z utilitarizmom in dekorativizmom,

11 Gl. Emery (2003). 
navzoča tudi v recepciji srednjega veka. Časovna in krajevna oddaljenost namreč velikokrat sovpadeta.

K tem štirim oblikam recepcije bi lahko pripomnili, da so delo akademske recepcije oziroma medievista/medievalista. S tem ko akademsko recepcijo postavita med ostale, pri čemer je akademska recepcija tu okvir in element hkrati, jo z ostalimi nekako izenačita. Drugače rečeno: tu lahko zopet opazimo, kako se razločevanje med medievistiko in medievalizmom kot recepcijo sesuje. Natančneje rečeno: strogi medievist ne obstaja. Če je medievistično lahko pomenilo, in ponekod je temu še vedno tako, profesionalno ali poklicno, znotrajakademsko, utemeljeno na raziskovanju, objektivno, zavezano razkrivanju avtentične preteklosti, medtem ko je bil medievalizem vse nasprotno, torej ljubiteljsko, zunajakademsko, osnovano na kulturnih predsodkih in predpostavkah, subjektivno ter oblikovano $\mathrm{z}$ individualnimi ali širšimi družbeno-kulturnimi potrebami in željami, pa sesutje ali prej brisanje meja med obema ne pomeni zgolj tega, da objektivno vodijo te ali one predpostavke in predsodki, temveč tudi to, da je vloga medievalizma videna drugače. Ni več znamenje ali točka spodletelega znotraj medievistike, točka nemožnosti je sedaj točka možnosti. Obenem ni dovolj trditi, da se polje le notranje zasuka ter da so stare koordinate objektivnosti in avtentičnega še vedno navzoče, da niso bile povsem jasno odpravljene. Enako ni zadosti reči, da posledično avtentična sodba ni mogoča, kar posebej velja za uradno in neuradno vejo pri skupnem vprašanju avtentičnega. Ključnega pomena je, da medievalizem vnaša vprašanje »sodobnega« oziroma sinhronega, natančno kot »modernost srednjega veka» - to je treba videti kot okrepitev, torej onstran lepodušniškega govorjenja o srednjem veku kot nekakšni nepredirni ali neujemljivi enigmi, pri čemer lahko z njim počnemo, kar se nam zahoče. Obenem si je treba natanko tu postaviti vprašanje objektivnega in subjektivnega, seveda na nekoliko drugačen način. Znotraj umetnostne zgodovine je to drugačno zastavitev prvi odprl ali nakazal prav Erwin Panofsky, v čemer lahko vidimo eno glavnih premen, in to ne le znotraj samega proučevanja srednjega veka. ${ }^{12}$

12 Na neki način se je treba resnično vrniti k Panofskemu (tu izhajam iz prispevkov v DidiHubermann, 2008) oziroma k vsem temeljnim umetnostnozgodovinskim tekstom nasploh. Glede preobrata Panofskyjeve ikonologije gl. tudi Wajcman (2007), predvsem z gledišča t. i. materialistične ikonologije, ki jo avtor vpeljuje. 
Če je medievalizem nenehen proces pisanja oziroma postavljanja srednjega veka, pa je treba, sledeč Clare A. Simmons, seči še nekoliko dlje: kar te štiri oblike recepcije zaobjemajo, je kulturna adaptacija ali "prilagoditev«, apropriacija ali "prisvojitev« (Simmons, 2001, 22). A tudi Clare A. Simmons ne gre dovolj daleč, prav zato, ker se oklepa ravni intence, namere, motivacije in hotenega. Če inkorporacija, sklicevanje na srednjeveška dela, torej kakršna koli adaptacija srednjega veka ali srednjeveškega dela ne vključuje hotenega sklicevanja na - tudi umišljeni - sistem vrednot, ki je veljal v srednjem veku, tega potem ne smemo opredeliti kot medievalizem. S tem želi izključiti parodijo, medievaleskno in antikvarnost, ki se s preteklostjo ukvarja dobesedno kot s preteklo preteklostjo, s srednjim vekom kot zgolj zgodovinsko kurioziteto. Pa vendar, če sprejmemo - in pravzaprav moramo sprejeti -, da je medievalizem vsakršna recepcija, potem nikakršno izločevanje »slabega vpliva «ne sme in ne more biti korektno oziroma v celoti verodostojno. Ko se Matisse iz povsem likovnih razlogov sklicuje na starorusko ikono, postane del medievalizma; medievaleskne rekonstrukcije srednjega veka v Parizu na prelomu stoletij so enako del medievalizma, tudi zgodovine medievistike, če se le spomnimo na prispevek umetnostnih zgodovinarjev, ki so skušali na prelomu stoletij usmerjati recepcijo občinstva. ${ }^{13}$

Temeljni uvid Clare A. Simmons in številnih drugih medievistov/medievalistov pa vsekakor velja zadržati: če je bil tok objektivnega in avtentičnega znotraj polja medievistike prevladujoč vse do začetka zadnje četrtine dvajsetega stoletja, so zagotovo že poprej, na splošno zopet na prehodu stoletij, obstajali znaki, da je treba samo vprašanje objektivnega in avtentičnega misliti in zastaviti drugače. To je zagotovo temeljni uvid same problematike medievalizma, ki pa vendarle ne zapade v vsesplošno pristranskost. Nedvomno ne gre zgolj za ponujanje novega, bolj dognanega odgovora. $\mathrm{Na}$ neki način je odgovor ali rešitev že drugačna zastavitev ali reformulacija istega vprašanja.

13 Gl. Emery (2003). 


\section{Objektivno-subjektivno: misliti materialnost in resnica brez jamstva}

$\mathrm{Z}$ ločevanjem med medievistiko in medievalizmom je bil že na samem začetku nakazan poglaviten razcep in $\mathrm{z}$ njim sama točka vzpostavitve medievistike kot akademske discipline, ki se v devetnajstem stoletju vzpostavi, dobesedno ustanovi ali instituira tako, da se z določeno gesto izloči iz popularne recepcije, s čimer pa se pravzaprav inavgurira tudi ta. Nenazadnje imamo tu opraviti prav z rojstvom zornega kota, kriterija, dobesedno okvirja, ki razmeji pravo od nepravega, resno od neresnega in neupoštevanja vrednega, nižje od višjega. Nedvomno pa ima ta premik ali zasuk, ki za nazaj ustvari sliko širokega polja medievalizma, v katerem prek lastne izločitve vznikne medievistika, določene posledice, vsekakor še vedno trajajoče, ne glede na vseprisotno kritiko očetov medievistike, na kar lepo opozarja delo Kathleen Biddick (Biddick, 1988, 1-4). V vsakem primeru se odpira vprašanje, ali je to že način, kako medievistika za nazaj pojasnjuje oziroma postavlja lasten izvor ali začetek vse do renesanse, seveda kot petitio principii najdevanja sebe ali predpostavljanje tistega, kar je že rezultat, z drugimi besedami: ko je rezultat enkrat že pred nami, ko se je performativno izrekanje ločitve že zgodilo. S samim izrekanjem se postavi ločnica in dvojica medievalizma in medievistike. Kot je morda že postalo jasno in kot bomo lahko še videli, je ta ločitev oziroma razločevanje med medievistiko in medievalizmom bolj kompleksno, tudi na dejstveni ravni, kakor ga velikokrat skuša predstaviti uradna veja. Kar je za eno generacijo srednji vek, je lahko za drugo zgolj še en primer v verigi medievalizmov ali recepcije, celo definicije srednjega veka in »srednjeveškosti« del.

Teza, ki jo Kathleen Biddick dokazuje in podkrepi s številnimi primeri, je naslednja: posledice interpretativnih metod, s katerimi se je medievistika ustanovila kot akademska disciplina, segajo v današnji čas. Ne gre zgolj za posledice, tudi same metode so še vedno v rabi. To seveda ni dokaz, da se devetnajstega stoletja, kritiki navkljub, v resnici ne moremo v celoti znebiti, da je naš poslednji horizont, temveč pomeni predvsem to, da je samo instituiranje medievistike odprlo prostor, na podlagi katerega se lahko kritika očetov šele prične. A vendar kritika ni dovolj učinkovita, zato ostaja vezana na očete: manjka ji bolj temeljito historiziranje, umeščanje razvoja 
medievistike v širši družbeno-kulturni oziroma politično-ideološki okvir. Kathleen Biddick se $s$ to opazko skorajda nujno zaplete $\mathrm{v}$ probleme, ki jih prinaša dvojica medievalizma in medievistike: $\mathrm{v}$ problem historicizma, ${ }^{14}$ tudi revizionizma, $v$ problematiko interpretacije, same napetosti ali antagonizma med zgodovino in zgodovinopisjem, med historičnim in historiografskim. Oblika, v kateri se tovrstna problematika kaže, je vprašanje zaznavanja potvorbe in avtentičnega. $Z$ drugimi besedami, vprašanje je že staro: kako potegniti mejo med avtentičnim in ponarejenim? Kaj je srednji vek? Kaj je srednjeveško, kaj medievistično oziroma medievalistično? Kaj je objektivno? Naloga se zdi v pretežni meri težka, ne samo z vidika periodizacije, postavljanja ločnic znotraj študijskega polja, še posebej ker smo vselej že udeleženi v "ponarejenem «. To nas lahko zopet vodi do ugotovitve, da bo lahko tudi današnja medievistika v prihodnosti dojeta kot še en medievalizem, ne glede na trenutno prevladujoči »realistični« poudarek na iskanju bridkih resnic srednjega veka mesa in krvi. Vprašanje je morebiti nepravo, morebiti ni dovolj natančno. Zato se velja vprašati, kdaj natanko in v kakšnih pogojih oziroma okoliščinah se to vprašanje pravzaprav pojavi, na čem poganja in kje so njegovi nastavki. Preden se ponudi odgovor, je treba storiti manjši deleuzijanski korak in reči: »Táko je torej vprašanje ...»

Jacques Rancière je v svojem imenitnem delu Les Noms de l'histoire: essai de poétique de savoir več kot nazorno pokazal srž problema in obenem same interpretacije, ki ni zgolj odslikavanje, temveč vseskozi strogo aktivno posega v svoj objekt, ga spreminja in pravzaprav šele postavi kot interpretabilni objekt, kot objekt, vreden interpretacije - skratka, kot (nujno potreben) objekt. Pri tem se je treba izogniti kreacionistični logiki, na katero bi se veljalo spomniti tudi ob že omenjenem primeru izrekanja ločitve medievistike od medievizma (Wajcman, 2007, 40 in 53). ${ }^{15}$ Vprašanje, ki se tako postavlja, je sledeče: kako misliti »moč neke prakse, da lahko proizvede

14 Kot pravi Joan Copjec (1995, 1-14): kaj drugega je dediščina devetnajstega stoletja kot vsi historicizmi, psihologizmi, sociologizmi in drugi determinizmi? Zelo pomembne so njene misli o utilitarizmu in funkcionalizmu, ki imata velik vpliv na recepcijo srednjega veka, kar velja upoštevati na primer vsaj pri Violletu-le-Ducu in kar se prenese, v zaostritvi, v prvo polovico dvajsetega stoletja. Zanimivo je tudi, kako tesno povezani sta dve kolikor toliko nasprotujoči si težnji: utilitarizem in eksotizem/dekorativizem (Copjec, 1995, 65-116).

15 Glede problematike interpretacije še: Žižek (1997), posebej poglavje o nasilju interpretacije, diskurzivizmu in historicistični kontekstualizaciji. 
svoj lasten objekt (srednji vek ali srednjeveško delo, medievalizem in medievistiko) onstran reprezentiranja, interpretiranja, posnemanja oziroma prikazovanja nekega objekta? « (Zupančič, 2001, 11) ${ }^{16}$ Lahko bi še dodali: kako opomniti na to (namerno ali nenamerno utajeno) razsežnost znotraj takšnega reprezentiranja?

Pri Rancièru je tako temeljno dvoje: prvič, sámo ime "zgodovina«, ki ima vsaj v francoskem jeziku to srečno lastnost, da pomensko hkrati obsega zgodovino v pravem pomenu besede, kot znanstveno obrazložitev, in zgodbico ali pripoved, lažno ali lažnivo fikcijo, zaradi česar nas nato ne sme presenetiti naslov morebiti ključnega poglavja, ki meri na problematiko pisanja: eksces besed, sam presežek besed ali razcep besede "zgodovina" na dve med seboj nasprotujoči si pomenski veji. »Boriti se z besedo«, pravi Rancière (Rancière, 1992, 1). Nadalje, drugič: "vsi lahko interpretirajo«, »vsi pišejo«, lahko bi rekli: »vsi lažejo«, v čemer je navzoča tudi strogo sekularna bitka, $\mathrm{v}$ prehodu od kronike $\mathrm{k}$ znanstvenemu zgodovinopisju in ob njem. ${ }^{17}$ Zaenkrat naj nakažemo le toliko, kot je, kot že rečeno, jasno razvidno iz naslova zgoraj omenjenega Rancièrovega dela: premik od $\mathrm{Ru}$ skina k Chestertonu. Enako zadeva jezik, prav problematiko označevalca, kar je tako rekoč (pred)strukturalistični moment, ki meri na odmik od pozitivizma in njegovih $\mathrm{v}$ pretežni meri naivnih pogledov, ki gredo $\mathrm{v}$ smeri adequatio, in ob čemer velja pripomniti, da sta strukturalizem in poststrukturalizem, kar je anglo-ameriška skovanka, ki ima vlogo koša, v katerega se je vrglo to ali ono ime »kontinentalne teorije«, v marsičem zasukala tudi študije o medievalizmu in medievistiko, še posebej v drugi polovici preteklega stoletja.

16 Tu se v veliki meri opiram na citirano delo Alenke Zupančič.

17 Rancièrovo delo je imelo velik vpliv na teoretike zgodovinopisja in kot v uvodu pripominja Kathleen Biddick (1998), tudi na študije o medievalizmu in medievistiki; v slovenskem prevodu zaenkrat še ni dostopno. Spopad $\mathrm{z}$ besedo oziroma $\mathrm{z}$ imenom, bolje rečeno označevalcem, je prisoten že v naslovu dela: dobesedno dve imeni zgodovine, pri čemer pa poetika vednosti meri prav na samorazcep besede oziroma označevalca. Poetika je tu natanko ta razcep oziroma neujemanje besede s seboj, kako samo besedo, strogo razcepljeno na dva nasprotna si pomena, ne na večpomenskost, od znotraj načenja presežek ali eksces, klica poetske globine. Kar jo načenja od znotraj, je prav sama ponovitev oziroma (tavtološko) ponavljanje besede $\mathrm{z}$ njo samo, kar je prav znamenje razcepa oziroma razcep sam: "zgodovina je ... zgodovina«. 
S partikularnega vidika umetnostnozgodovinske medievistike je treba dodati, da je pri vprašanju jezika in vsaj minimalnem odmiku od pozitivizma, ki se dogodi z nekaterimi umetnostnozgodovinskimi deli v prvi polovici dvajsetega stoletja, na to problematiko natančno opozoril Pierre Bourdieu, in to na podlagi svojega prevoda in komentarja sicer ostro, a velikokrat neupravičeno kritizirane Panofskyjeve knjižice o gotski arhitekturi in sholastiki, z osrednjim problemom strukture in generirajočega ter terminom in konceptom habitusa, ki ga Panofsky izvleče iz Summae Theologiae Tomaža Akvinskega. ${ }^{18} \mathrm{~V}$ Panofskyjevi knjižici je, ne glede na kritike, nastavljeno tako rekoč vse bistveno, pravzaprav se je treba vselej nasloniti na te točke in jih poiskati: gre za vprašanje objektivnega in subjektivnega $\mathrm{v}$ povsem novi luči. Sem bi lahko zlahka umestili tudi problematiko t. i. mentalité, ki jo postavi in razvije francoska šola Annales. Tu se prav tako odpira prava misel o materialnem, ki podpira netransparentno oziroma poudarja moč neprosojnega ${ }^{19}$ Polje, ki se s temi termini zarisuje, je natanko presek med objektivnim in subjektivnim, rob med obema, kjer se stakneta, vendar ne kot sinteza. Ali ne gre pri hkratnem vprašanju medievalizma kot strogo subjektivnega in medievistike kot strogo objektivnega prav za mišljenje pravkar omenjenega »polja«, preseka ali roba? Natanko to je temeljni uvid

18 Gl. Bruce Holsinger (2005); delo zelo problematičnega naslova (predmoderno je produkt moderne, je način, kako se ji kaže lastna zagata, ne zgolj kot nevarnost padca v predmoderno ali »regresija «) - delo je pregled medievalizma skozi dela vélikih teoretikov dvajsetega stoletja, vključuje pa prevod Bourdieujevega komentarja iz leta 1967 in avtorjev komentar komentarja. Kot je znano, se je Bourdieu, katerega prevod Panofskyjeve knjižice je bil vse do Foucaulta zelo odmeven, nekaj let kasneje upravičeno oddaljil od Panofskyja, za katerega se izkaže, da je imel vse pripravljeno, a ne do konca izpeljano: Bourdieu mu očita premočno naslanjanje na opus operatum, ne pa na modus operandi, umetnostnim zgodovinarjem pa, kar je bilo že omenjeno, še vedno nepretrgano vez z ljubiteljskim poznavalstvom. Četudi je koncept habitusa izjemnega pomena, pa ga je treba $\mathrm{z}$ dvojico objektivno/subjektivno misliti nekoliko natančneje, kot je pripravljen storiti Bourdieu: habitus ni preprosto objektivno, ni zgolj subjektivno, prav tako ni subjektivno-objektivno, temveč strogo objektivno-subjektivno (naj znova opomnim na prej omenjeno problematiko materialne iskrenosti). V tem je očitna navezava na psihoanalitični koncept fantazme. Sicer pa je teorija psihoanalize, psihoanaliza kot miselni dogodek, v teoriji medievalizma točka šibkosti, kar Clare A. Simmons jasno podčrta $\mathrm{v}$ uvodu zbornika (2001). Poudarek je pomemben zaradi topik, ki jih srečujemo v medievalizmu: melanholija, žalovanje, izvor, izguba, travma, drugost. Predvsem zadnji dve sta teoretsko najbolj problematični, še posebej njuna aktualno pretirana (iz)raba.

19 Gl. Žižek (1997, 9-13 in od 139 dalje). Za t. i. analiste, zgodovino šole, gl. Rancière (1992). Misel o materializmu kot podelitvi polne veljave neprosojnemu je Wajcmanova (2007). 
problematike medievalizma in habitusa, ki ga številni zgrešijo: objektivnosubjektivno. Pomembno je vztrajati pri tej točki napetosti, kjer sta si medievalizem in medievistika hkrati kar najbližje in najdlje.

Omembe vredna sta vsaj še dva prispevka, tesno povezana $\mathrm{z}$ nakazanim odmikom, Worringerjev in Wölfflinov. Hans Belting opomni, da je bil Heinrich Wölfflin eden prvih, ki je ekspresionizem, izhajajoč iz nemške avantgarde, uporabil anahronistično, in to $\mathrm{v}$ širšem pomenu besede - da je to širšo rabo, vsaj znotraj umetnostne zgodovine in skupaj z drugimi, iznašel (Belting, 1998, 49-60). ${ }^{20}$ Morda je njegovi interpretaciji Bamberške apokalipse vse prelahko očitati anahronizem ali le vnazajšnje iskanje in detektiranje pristno nemškega, po ekspresionizmu a posteriori že od vselej navzočega, za nacionalna tla karakterističnega. ${ }^{21}$ Enako velja za Worringerjeve gotske katedrale. ${ }^{22}$ Ta dediščina je prisotna tudi v sociološki veji umetnostne zgodovine, najdemo jo na primer pri Arnoldu Hauserju, ko govori o ekspresionizmu pozne antike in zgodnjega krščanstva, pri čemer pa nadvse jasno naznači, za kaj gre: za psihologijo, če dodamo: psihologiziranje (Hauser, 1969, 162-163). A zadaj je kljub temu še neko drugo iskanje, iskanje nekega drugega ustroja, v ozadju je drugačna, materialistična pozornost na obliko, formo, na sam videz ali način, kako se srednjeveško delo ali objekt pojavlja, kako se kaže in kako je zgrajeno. ${ }^{23} \mathrm{~A}$ vendarle se

20 Za vprašanje anahronizma in umetnostne zgodovine gl. uvodno poglavje spodaj navedenega dela Georgesa Didi-Hubermana (2000), in sicer o umetnostni zgodovini kot anahronistični disciplini. Naj pri Wöllflinu poudarim naslednje: ne gre za neposredno rabo besede ekspresionizem, temveč za vzpostavljanje paralele med otonsko iluminacijo in razvojem modernega slikarstva v Nemčiji, seveda ekspresionizmom - skupaj z vprašanjem, kot pripominja, (upada) naturalizma. Že na uvodni strani (Wöllflin, 1921, 5) nas čaka prav taka misel: ".... in auffallender Parallelität zu gewissen Entwicklungen der modernen Malerei...»

21 Pri Wöllflinu (1921) - in ne samo pri njem - se zna še dodatno zaplesti: v sami aplikaciji ekspresionizma na srednjeveško delo je še vedno mogoče začutiti staro topiko adequatio, še posebej kar se tiče tedanjih problemov nemške umetnostne zgodovine in politične situacije v Nemčiji, kar je bilo že omenjeno - torej iskanje nacionalnih karakteristik v umetnosti, avtentificiranja nacionalnega. Rabo anahronizma očitno lahko mobilizira marsikaj (Belting, 1998, 77-78).

22 Tu se opiram na dognanja zbornika, ki ga je uredil Donahue (1995).

23 Izjemen prispevek k zasledovanju forme je v tem primeru članek Herberta Kesslerja (1988), predvsem z gledišča tistega, čemur sam pravi recikliranje $\mathrm{v}$ srednjem veku, seveda glede ustroja samih del. Lahko bi rekli, da je tudi pri njem resnica tam zunaj, seveda prek usmeritve pozornosti na materialno zunanjost srednjeveških del. 
problem anahronizma tu ne ustavi. Moramo ga dojeti kot indic premika moderne, zasuka, ki je kratko malo moderna doba: anahronizem preprosto ni zgolj slogovna figura ali kaprica, ni zgolj revizionizem, časovna zmota ali časovno neskladje, vnazajšnja prisvojitev, ki na videz vse dopušča, temveč je sam zaznamek moderne dobe, način, kako se ta kaže v pisanju in kako se v njem zaznamuje - prav kot diskurzivno uokvirjenje pripovedi. Natanko to razvija Jacques Rancière, ko govori o rabi besed izven njihovega konteksta (Rancière, 1992, 53-88). V čem je škandaloznost takšne anahronistične rabe, poleg samega mišljenja vmesnega prostora med dvema, med objektivnim in subjektivnim? Časovno neskladje kaže, da je vsak dogodek, nenazadnje vsaka instavracija, ustanavljanje, povezan $\mathrm{z}$ določenim presežkom besed, in sicer v specifični obliki premeščanja določenega rekanja: gre za prisvojitev besede drugega. Prisvojitev pa je dejstvo drugačnega označevanja ali pomenjanja, ki v sedanjem prinaša odmev preteklega in obratno. Anahronizem kot nepravšnjost izraza je torej času neprimerna nadstavitev, pa vendar vanj vnaša določen razcep, ga za trenutek izpahne in nanj vrže drugačno luč. Njegov primer je znan: francoska revolucija, oblečena po antično, Bamberška apokalipsa, oblečena v ekspresionizem in obratno: Malevičeva dela, oblečena v starorusko ikono. $V$ tem je že mogoče zaslutiti razliko med pripovedovanjem ali upovedovanjem nekega dogodka - samo izrekanje je že lahko dogodek - in nenehnim interpretiranjem, ki skuša zajeziti tudi svoje lažne besede, pa naj bodo to besede same revolucije ali besede o revoluciji. Med dejstvi in interpretacijo je gost oblak besed, ki ga je treba presekati. Kako se ne pustiti ujeti besedam, kako ostati neprevaran?

Boj proti anahronizmu in/ali potvorbi, ki je lahko sama dogodek ali znamenje historičnega, je tako interpretativni in interpretacijski boj proti napačnim interpretacijam, katerih besede vnašajo ekspresionizem v čas, ko ni obstajal. Nevarnost je vsaka dvoumnost, neavtentično in primanjkljaj ustreznih, adekvatnih besed. Stremljenje po najdenju adekvatnega, "ustreznega«, ima mnogo preoblek. V ospredju je tako sam razmik med besedami in rečmi: tu ni nikakršne harmonije, pri čemer pa velja poudariti, da to ni problem interpretov, temveč samih udeležencev nekega dogodka ali preteklega časa: maksima revizionizma je prav ta, da se ni zgodilo nič takega, kar je bilo rečenega, nihilistična pa pravi, da se pravzaprav nič ni zgodilo. To nas vodi k odsotnosti objekta, samemu izničenju zgodovine kot 
znanosti, in sicer prav skozi določeno smer (ali prek nje), ki je del znanstvenega zgodovinopisja. Med razmerje preteklega in sedanjega se tako naseli stigma lažnega, popačenega, neavtentičnega. Prav ta stigma je še en način, kako se kaže temeljna napetost med historičnim in historiografskim, med »lažno" obleko revolucije in resnico, ki je na strani historiografije, katere pogoj pa je prav sama »lažna« obleka, nje sprevid, nastop dvojice lažno/ pravo, kar se nato tudi preslika na samo raven pisanja, kot vidimo na primeru anahronistične rabe ekspresionizma. Problem je vseskozi problem jezika, spopad z besedo in neobstojem metagovorice. Reči, da metagovorice ni, seveda najprej pomeni, da ni govorice kot $\mathrm{v}$ sebi sklenjene celote, da sta razcep oziroma dvoumje njen sestavni, inherentni del. Zastavek metagovorice je navzoč v sami možnosti slojenja, ki sledi preprosti logiki $n+1$, da se lahko določeni ravni, sedaj dojeti kot nižji, nadstavi višja, ki jo lahko do potankosti zaobjame, celò in morda predvsem z opisom. Logika nenehnega nadstavljanja vselej višje ravni pa kaže prav nasprotno: da nekaj uhaja. Prav disjunkcija med interpretacijo in objektom je način ali točka, $s$ katero in $\mathrm{v}$ kateri je sam interpret vpisan v lastno delo. ${ }^{24} \mathrm{Z}$ drugimi besedami: natanko to so posledice vzpostavitve $-s$ samim instituiranjem in razmejevanjem se ta problem popačenja in resnice šele postavi oziroma rodi. $V$ tem pa je tudi poganjek ali klica rojstva ideala objektivnosti, ki vznikne hkrati z vprašanjem perspektivičnosti in resnice:

24 Gl. Pierre Bourdieu, v Holsinger $(2005,242)$; opozori nas prav na to, in sicer, ko se sklicuje na znamenito Panofskyjevo izjavo, da se za razliko od naivnega gledalca umetnostni zgodovinar zaveda, kaj dela, da se lahko sproti očisti vseh implicitnih predpostavk, ki obarvajo njegovo percepcijo in misel. To izjavo sopostavi izjavi Saussura in Benvenista (prevedel avtor pričujočega članka): »... Erwin Panofsky presenetljivo razkriva, da lahko počne to, kar počne, zgolj pod pogojem, da lahko v vsakem trenutku ve, kaj dela in kaj je za to delo potrebno, saj so najbolj ponižni in najbolj vzvišeni znanstveni postopki vredni največje teoretske in epistemološke zavesti, ki jih spremlja." To striktno, tako rekoč po pravilu, ni venomer mogoče. Rešitev preprosto ni dovolj močna, potrebuje pa razdelavo navezave Panofskyja in novokantovstvo Ernsta Cassirerja; drugače rečeno: tistega, na kar opozori Bruce Holsinger - na Kantovo transcendentalno apercepcijo, samozavedanje ali zavedanje zavedanja, ki spremlja vsako dejanje našega zavedanja (Holsinger, 2005, 94-113). Če želimo, lahko vsakič obrnemo pozornost na lastno dejavnost, si stopimo za hrbet, tudi znotraj določenega časovnega razmika, znotraj vnazajšnjosti. Problem je v tem, da je to strogo virtualna točka, ki pa ima posledice prav kot taka, kot sama možnost samozavedanja. 
"Ne gre za vprašanje, kaj je (in če je) realna substanca objekta onstran našega »opisnega« spoznanja. Tisti »čudež«, ki se ga spoznanje kot »opis« ne dotakne $[. .$.$] , je notranji samemu »opisu« oziroma »pojavu«.« (Zupan-$ čič, 2001, 89)

»Problem sveta kot "podobe« je seveda korelativen temu, kar Nietzsche imenuje "perspektivično gledanje«. Poanta tega gledanja namreč ni samo parcialnost, fragmentarnost in umeščenost našega spoznanja, temveč vsaj toliko tudi njegova »omejenost « na modus podobe. Nietzsche večkrat poudari, kako je za spoznavajočega ključna sposobnost in spretnost menjavanja perspektiv, "zornih kotov«, in bolj ko smo vešči v tej "gimnastiki«, celovitejše bo naše spoznanje objekta, popolnejša bo podoba, ki jo imamo o njem. A prav za to gre: tu smo še vedno na ravni podobe kot »opisnega « spoznanja, »spoznavnega realizma«, če lahko tako rečemo, kar najnatančnejše reprodukcije oziroma reprezentacije. In čeprav lahko rečemo, da je takšno spoznanje objektivnejše od tistega, ki se zadovolji z eno samo perspektivo, se lahko objektivnemu spoznanju le asimptotično približuje. Toda Nietzschejev ideal objektivnosti ni nemogoča celota vseh perspektiv in prav zato, bi lahko rekli, objektivnost pri njem ni ideal. Objektivnost kot ideal (ali regulativna ideja) znanosti je izraz njene nemožnosti, da bi bila kdajkoli zares objektivna. Vselej (in konstitutivno) ji bo nekaj ušlo na drugo stran.« (Zupančič, 2001, 90-91)

V zasuku od Ruskina k Chestertonu je treba upoštevati prav logiko oziroma nasledek Nietzschejeve diagnoze lastnega časa. Z drugimi beseda$\mathrm{mi}$, kar se tu spremeni, je sama narava resnice. To je strogo povezano $\mathrm{s}$ problematiko jezika in odmikom od adequatio. Resnica ni več vezana na dejstveno oziroma faktično, ni več vezana na par pravo/lažno. Nenazadnje je samo popačenje, sama potvorba je tista, ki je potrebna pojasnitve, in to $\mathrm{v}$ vseh svojih učinkih in učinkovanjih. ${ }^{25}$

25 Gl. poglavje Zgodovina in ponavljanje I: kako »resnica vznikne iz sprevida«, v Žižek (1982); pri vprašanju medievistike in medievalizma je treba upoštevati pomislek, kako ne zapasti nezgodovinski logiki iskanja izvirnega pomena ali izvirne historične podobe, sledeč kateri bi bili vsi kasnejši pomeni zgolj drugotne interpretacije - upoštevati moramo praktični produktivni pomen naknadnih filtriranj (Žižek, 1982, 109). Medievalizem in medievistika si delita to logiko avtentičnega, pa tudi vživljanja, na kar lepo meri naslov dela, ki ga je uredila Clare A. Simmons (2001). 
Temelj medievistike kot institucije je torej, sledeč Kathleen Biddick, t. i. metodologija osamitve, dobesedno izoliranja. Bistvena momenta ločitve medievistike od medievizma sta na eni strani sama ločitev, torej strogo $i z$ rekanje same ločitve in/ali osamitve, ki zaznamuje rojstvo določenega zornega kota, pod vplivom znanosti in pozitivizma: ločitev je že sama po sebi povzdignjenje nad popularnim, sedaj že neznanstvenim. Izrekanje tako ni zgolj nekakšna nedolžna retorična igra, posledice so namreč daljnosežne. Njegov objekt ni, če si izposodimo izraz Gérarda Wajcmana, »materialna beseda « ${ }^{26}$ »srednji vek, medievalizem in medievistika, zvedeni na svojo izjavljalno funkcijo«. Tu skratka ne gre za skrajni diskurzivizem. Vse, kar je sedaj dojeto - in pogojno rečeno dokazano - kot neznanstveno, dobi označitev medievalizem, kamor spada tudi medievaleskno. Slednje je prav tista konotacija, ki obarva oziroma $\mathrm{z}$ vidika akademske recepcije daje podtalni pomen tej novonastali označitvi: vrednost pastiša, zabavljaškega, neresnega, oponašalnega, imitacije, bolj ali manj brez osnove ali kriterija oziroma brez kakršne koli utemeljenosti v dejstvenem. Na drugi strani pa ima ta ločitev obliko še ene bistvene točke: srednjeveška dela, kar artefakte, so ne samo znotrajmetodološko ločili od tedanjega konteksta, s čimer so utajili sinhrono in pogled lastnega časa, kakor da so se lahko izvzeli iz njega, temveč $\mathrm{v}$ precejšnji meri tudi od konkretnega materialnega konteksta dela, ${ }^{27}$

26 Gl. Wajcman (2007).

27 Vsaj kar se srednjeveških del tiče, to še vedno ostaja problem. Gl. Kessler (1988). Članek je ključnega pomena, ker identificira temeljne probleme sodobne umetnostnozgodovinske medievistike: periodizacijo, status dela, »umetnika«, vprašanje sloga itn. Naj tu dodam lastno opazko, vsaj kar se tiče metode, predvsem mišljenja atribuiranja in pripisovanja v širšem pomenu besede. Lahko bi rekli, da tradicija pripisovanja, sicer nujna in neobhodna, ki pa kljub temu ni naš poslednji horizont, umetnost pretežno zvaja na obrt oziroma veščino prav zato, da ohranja lastno konsistenco. Gérard Wajcman zagovarja naslednje (Wajcman, 1999, 62-64): "Bomo sedaj rekli: in bretonska umetnost in židovska umetnost in še druge? Ideja nekakšne »lokalne umetnosti« se upira ideji Umetnosti. Najmanjša slika, ki jo je naslikal japonski slikar na Japonskem, na japonski svili, z japonskim čopičem, z japonskimi črnili, v skladu z najbolj tradicionalnimi pravili umetnosti Japonske, upodabljajoč značilno japonsko krajino in vsebujoč vanjo vpisano kaligrafsko pesem z japonskimi pismenkami, $\mathrm{v}$ jeziku in pisavi, ki sta veliki večini človeštva popolnoma neznana, prav ta najmanjša slika se kot umetniško delo strogo drži v univerzalnem, po pravilu se drži v univerzalnem, vzporedno z vsemi univerzalnimi subjekti, ki jo, od severa do juga, od vzhoda do zahoda, sprejemajo kot njim pripadajočo in usojeno. $\mathrm{V}$ umetnosti ni ne eksotizma ne tujine. Nenazadnje, vsaka umetnost, ki bo predvidevala meje, ne bo umetnost. "Lokalna umetnost « bo zgolj razkazovala in hvalila partikularizme, ki se zoperstavljajo univerzalnosti, v nasprotju 
obenem pa velikokrat tudi, presenetljivo, od časa in kraja nastanka dela. Obravnavali so jih kot fosile. Trije med glavnimi predstavniki te metodologije osamitve so: znotraj literarne zgodovine in komparativistike Gaston Paris, ki uvede dokumentarizem branja in interpretiranja srednjeveške poezije, znotraj umetnostne zgodovine Viollet-le-Duc s svojim konzervatorskim formalizmom predstavlja enako zagato, v zgodovini pa na primer Bishop Stubbs, ki se časa pred sedemnajstim stoletjem ne želi lotevati zgodovinsko (Biddick, 1998, 1-4).

Podobno zopet razvija Rancière: zgodovinske znanosti se prek poudarkov na viru, dokumentih, geografiji, statistiki, ekonomiji in demografiji vzpostavijo kot zoperstavitev t. i. histoire amusante, zabavni zgodovini, in zgodovinskemu romanu (Rancière, 1992, 9-12). Ti poudarki so snov zgodovinske zgradbe oziroma konstrukcije, kar pomeni, da zgodovinski material zunaj zgradbe ali ogrodja ne pomeni ničesar. $\mathrm{V}$ tem je poglavitna razlika med učenostjo, kultiviranostjo enciklopedičnosti ali seznanjenostjo, to je med nekaj vedeti in imeti potrebo to misliti. Toda metode niso prinesle tako zaželene gotovosti. Hkrati se je rodila vnazajšnja projekcija, da je doba kronike in kronistov ponujala več gotovosti, tudi v razmejevanju lažnega in resničnega. Tudi medievalizem, kot je bilo že rečeno, vseskozi spremljajo sanje o preteklem družbenem redu, jasnosti in urejenosti, ki se z moderno izgublja. Z nastopom zgodovinske znanosti nastopi neosebno, vse postane težje razločljivo in $\mathrm{v}$ samem delu ali postopanju je navzoča težnja, da se skozi samo iskanje jasnosti in nenehno zamejevanje nedoločljivost

s singularnostjo, ki je srž umetnosti. Delo, ki pripada umetnosti, ki je singularnost, je torej univerzalno. Vsaka lokalna umetnost, prav kolikor je lokalna, ni umetnost. Tu bi lahko zoperstavili obrt in umetnost. Obrt se osnuje na partikularnem. Partikularnosti obrti so generične: pričakujemo, da bodo vsi izvezeni prti iz Brugga imeli iste značilnosti. Generične partikularnosti obrti so takšne, da jih lahko povežemo oziroma jih moramo povezati s kraji, z zamejenimi geografskimi prostori, ki so lahko vedno ožji, partikularizirani. [...] Tako bomo lahko na primeru takšnega dela dodali vse partikularnosti kraja, časa, slogov in vsega, kar bomo želeli, to delo bomo lahko pripisovali, kolikor bomo želeli, tej delavnici, tej šoli, tej deželi, a bo kljub temu obdržalo svojo afirmacijo univerzalnosti, saj je edina univerzalna stvar singularnost. Od tod dejstvo, da je pri umeščanju določenega umetniškega dela edina stvar, ki jo namesto povezovanja generične partikularnosti določenega objekta $\mathrm{z}$ določenim partikularnim lokalnim prostorom lahko storimo, priključitev singularnosti objekta določenemu subjektu, vselej singularnemu, kar rečemo v obliki 'Velázquezove Spletične' ali 'Manetova Olimpija'.« 
referenta in inference priženeta do skrajnosti. Kar jo vseskozi spremlja, je zopet razcep zgodovine na dve pomenski veji: lahko bi rekli, da se ta dvopomenskost med zgodovino zgodbo in zgodovino znanostjo vrine $\mathrm{v}$ samo polje slednje oziroma se $\mathrm{z}$ njeno vzpostavitvijo porodi. Ta razlika mora biti vseskozi jasna, vidna, mora se proizvesti.

Zgodovini se tako ni treba braniti kakršnega koli vdora tujosti. Edino, kar mora storiti, je to, da se spoprime in pomiri s svojim imenom. Pomiriti se mora $\mathrm{z}$ lastnim imenom $-\mathrm{z}$ označevalcem (Rancière, 1992, 208). Ko zgodovini dodamo še umetnost oziroma »umetnostna«, se morda zdi, da okoliščine postanejo dvojno zapletene, a v nekem smislu še toliko bolj jasne. Medievalizem prinaša dokaj benjaminovsko opazko, predvsem $\mathrm{z}$ vidika razmerja umetnosti in njenih zgodovinskih okoliščin: da je umetniško delo ahistorično (Benjamin, 1992, 123). V tem smislu so umetniška dela bliže filozofskim sistemom, saj se specifična historičnost umetniških del ne manifestira kot taka, temveč v njihovih interpretacijah, ki kratko malo so umetnostna zgodovina. Interpretacije pokažejo ali izpostavijo določene korelacije med deli in njihovim časom oziroma lokaliteto - pravzaprav so te interpretacijske korelacije tiste, ki imajo $\mathrm{v}$ resnici neko resnično, pravo zgodovinsko pertinentnost. Zato moramo vsakič znova odgovoriti na vprašanje: kako to, da se lahko z umetniškimi deli ukvarjamo ne glede na kontekst, v katerem so nastala, da lahko torej učinkujejo onkraj časa in kraja, v katerih so nastala - da se lahko z njimi ukvarjamo še danes? Natanko $\mathrm{v}$ tem je ena od komponent paralele s filozofskimi sistemi.

\section{Od Ruskina k Chestertonu}

V luči boja $\mathrm{z}$ besedo lahko torej sprejmemo misel, ki jo v svojem članku razvije Chene Heady (Simmons, 2001, 131-143). Če je dolgo veljalo, da je Ruskinovemu medievalizmu in njegovi umetnostni zgodovini v soočenju z industrijsko revolucijo in zagatami moderne lahko le spodletelo, pa G. K. Chestertonov minimalni zasuk leta 1913, ki iz Ruskinovega dela pravzaprav izvleče in razvije tisto, kar je v njegovi misli že prisotno, to linijo misli o srednjem veku v premeni prenese v dvajseto stoletje. Ko Chesterton 
govori o neberljivosti znakov, o problemu ustvarjanja pomena, kar dobesedno povzema moderno, njemu lastni čas, poantira tisto ključno točko napetosti: neberljivost znakov, ki se upirajo, ne pustijo se nam brati, oziroma popolno deflacijo pomena. Izhajajoč iz korelativnega upada božjega in svetega srednji vek opredeli kot čas, v katerem je vsak znak, zahvaljujoč kompleksnemu, rigoroznemu, a arbitrarnemu družbeno-kulturnemu sistemu, označeval ali pomenjal točno, jasno, onkraj nestalnosti (Simmons, 2001, 138).

Zasuk je minimalen, a daljnosežen: lahko bi rekli, da je tu srednji vek zopet viden in dojet kot »idealni« družbeni red, a Chestertonov uvid je za razliko od Ruskinovega prav v arbitrarnosti, ki pa ima še določene podtone: lahko se dogodi, najprej se povrnimo h krščanstvu, pa se bo dogodilo samo od sebe, tako kot se je v srednjem veku. $S$ tem ko se povrnemo, se že dogodi. Vsi znakovni sistemi so umetni, a srečno spojenost označevalca in označenca, ki jo bojda izpričujejo srednjeveška dela, je mogoče doseči, s povratkom nazaj $\mathrm{h}$ krščanstvu, kar do določene mere pojasnjuje val ( $r e$ ) katolizacije, ki so ga sprožila nekatera Chestertonova dela. A vendarle je treba zaključiti tudi nasprotno: ko se v medievalizem skozi vprašanja ločitve, razmika, umiranja, minevanja, melanholije in žalovanja enkrat prikrade kontingenca, ki je nenazadnje odeta v poprejšnja vprašanja, povratka ni. Srečno spojenost, ki se jo po njegovem da doseči, se k njej vrniti, ker se je nekoč preprosto zgodila (in se zato lahko znova dogodi), bo kontingenca vsakič znova načela, a tudi porodila, tako da je Chestertonov minimalni, a globoki zasuk natanko $\mathrm{v}$ tem, da pokaže, na čem medievalistični ideali poganjajo, kje je njihov zastavek. Na neki način je tu na delu začaran krog, značilen tudi za moderno umetnost: Chesterton (nehote) razkriva klico religioznega, kje natanko se rojeva, in enako velja za ideal, a kljub temu ju (tudi dejstveno) prav s tem privablja. Bolj ko razkriva, bolj privablja - tudi poglabljanje enigme namreč -, s tem pa vnovično inflacijo pomena. ${ }^{28}$

28 Gl. Wajcman (2007). 


\section{VIRI IN LITERATURA}

Belting, H., The Germans and Their Art: A Troublesome Relationship, New Haven \& London 1998.

Benjamin, W., L' Ange de l'histoire, Pariz 1992.

Biddick, K., The Shock of Medievalism, Durham \& London 1998.

Chesterton, G. K., The Victorian Age in Literature, London 1961.

Copjec, J., Read My Desire: Lacan Against the Historicists, Cambridge, Massachusetts \& London 1995.

Didi-Huberman, G., Devant le temps, Pariz 2000.

Didi-Huberman, G. in drugi, Relire Panofsky: principes et théorie de l'histoire de l'art, Pariz 2008.

Donahue, N. H. in drugi, Invisible Cathedrals: The Expressionist Art History of Wilhelm Worringer, University Park, PA 1995.

Emery, E., Consuming the Past: The Medieval Revival in Fin-de-Siècle France, Aldershot 2003.

Gentry, F., The Reception of the Middle Ages in Germany: An Overview, Studies in Medievalism, III/4.

Hauser, A., Socialna zgodovina umetnosti in literature I, Ljubljana 1969.

Holsinger, B., The Premodern Condition: Medievalism and the Making of Theory, Chicago \& London 2005.

Kessler, H., »On the State of Medieval Art History «, The Art Bulletin, LXX/2, 1988.

Panofsky, E., Gothic Architecture and Scholasticism: Inquiry Into the Analogy of the Arts, Philosophy, and Religion in the Middle Ages, New York 1967.

Rancière, J., Les Noms de l'histoire: essai de poétique de savoir, Pariz 1992.

Ruskin, J., Pre-Raphaelitism: Lectures on Architecture and Painting, London 1907. 
Ruskin, J., The Stones of Venice, New York, London 1979, http://www.archive.org/stream/lecturesonarchit033432mbp <12. 9. 2009>.

Simons, J. in drugi, From Medieval to Medievalism, London 1992.

Simmons, C. A. in drugi, Medievalism and the Quest for the »Real "Middle Ages, London \& Portland OR 2001.

Wajcman, G., Collection, suivi de l'Avarice, Caen 1999.

Wajcman, G., Objekt stoletja, Ljubljana 2007.

Workman, L. J., Editorial, Studies in Medievalism: Medievalism in France 1500-1700, III/1.

Workman, L. J., Medievalism, The Year's Work in Medievalism, X, 1995.

Wölfflin, H., Die Bamberger Apokalypse: Eine Reichenauer Bilderhandschrift Vom Jahre 1000, München 1921.

Zupančič, A., Nietzsche: filozofija dvojega, Ljubljana 2001.

Žižek, S., Kuga fantazem, Ljubljana 1997.

Žižek, S., Zgodovina in nezavedno, Ljubljana 1982. 


\title{
MEDIEVALISM: FROM RUSKIN TO CHESTERTON
}

Keywords: Middle Ages, reception, medievalism, medieval studies, medievalesque, art history, objective-subjective

\begin{abstract}
This article deals with the topic of medievalism as all existing, still evolving, and future forms of reception of the Middle Ages, focusing primarily on the issues of the term itself and the problems that arise with its definition, its occurrence in John Ruskin's time, various historical forms, and their variations, especially considering some of the implications of its official or academic aspect - namely, medieval studies in general. Consequently, the article shows that medievalism entails a step beyond or beneath the usual opposition between the real and false Middle Ages. In terms of objectivity as an ideal, as the search or quest for the real Middle Ages (and also as a reaction against subjective receptions, colored by presuppositions, preconceptions, and prejudice), medievalism shifts our perspective on the opposition between the objective and subjective, inaugurating a field of study that centers on the objective-subjective, which should not be seen or taken as a synthesis. Furthermore, it pinpoints a change or shift in the status of truth itself: a truth with no guarantee. Primarily making reference to art history, the article emphasizes the importance of medievalist fantasies and proposes a much needed re-reading of Panofsky's take on the scholastic habitus. Both terms, fantasy and/or habitus, permeate the field of medievalism, opening what is perhaps the most important question: that of (works of art and) materiality.
\end{abstract}

